\title{
NONMONOTONE SPECTRAL PROJECTED GRADIENT METHODS ON CONVEX SETS*
}

\author{
ERNESTO G. BIRGIN ${ }^{\dagger}$, JOSÉ MARIO MARTÍNEZ ${ }^{\dagger}$, AND MARCOS RAYDAN $\ddagger$
}

\begin{abstract}
Nonmonotone projected gradient techniques are considered for the minimization of differentiable functions on closed convex sets. The classical projected gradient schemes are extended to include a nonmonotone steplength strategy that is based on the Grippo-Lampariello-Lucidi nonmonotone line search. In particular, the nonmonotone strategy is combined with the spectral gradient choice of steplength to accelerate the convergence process. In addition to the classical projected gradient nonlinear path, the feasible spectral projected gradient is used as a search direction to avoid additional trial projections during the one-dimensional search process. Convergence properties and extensive numerical results are presented.
\end{abstract}

Key words. projected gradients, nonmonotone line search, large-scale problems, bound constrained problems, spectral gradient method

AMS subject classifications. 49M07, 49M10, 65K, 90C06, 90C20

\section{PII. S1052623497330963}

1. Introduction. We consider the projected gradient method for the minimization of differentiable functions on nonempty closed and convex sets. Over the last few decades, there have been many different variations of the projected gradient method that can be viewed as the constrained extensions of the optimal gradient method for unconstrained minimization. They all have the common property of maintaining feasibility of the iterates by frequently projecting trial steps on the feasible convex set. This process is in general the most expensive part of any projected gradient method. Moreover, even if projecting is inexpensive, as in the box-constrained case, the method is considered to be very slow, as is its analogue, the optimal gradient method (also known as steepest descent), for unconstrained optimization. On the positive side, the projected gradient method is quite simple to implement and very effective for large-scale problems.

This state of affairs motivates us to combine the projected gradient method with two recently developed ingredients in optimization. First we extend the typical globalization strategies associated with these methods to the nonmonotone line search schemes developed by Grippo, Lampariello, and Lucidi [17] for Newton's method. Second, we propose to associate the spectral steplength, introduced by Barzilai and Borwein [1] and analyzed by Raydan [26]. This choice of steplength requires little computational work and greatly speeds up the convergence of gradient methods. In fact, while the spectral gradient method appears to be a generalized steepest descent method, it is clear from its derivation that it is related to the quasi-Newton family of methods through an approximated secant equation. The fundamental difference is

* Received by the editors December 3, 1997; accepted for publication (in revised form) June 15, 1999; published electronically June 13, 2000.

http://www.siam.org/journals/siopt/10-4/33096.html

${ }^{\dagger}$ Departamento de Matemática Aplicada, IMECC-UNICAMP, CP 6065, 13081-970 Campinas SP, Brazil (ernesto@ime.unicamp.br, martinez@ime.unicamp.br). The research of the first author was sponsored by FAPESP (grant 95/2452-6). The research of the second author was sponsored by FAPESP (grant 90/3724-6), CNPq, and FAEP-UNICAMP.

$\ddagger$ Departamento de Computación, Facultad de Ciencias, Universidad Central de Venezuela, Ap. 47002, Caracas 1041-A, Venezuela (mraydan@reacciun.ve). This author's research was sponsored by FAPESP, FAEP-UNICAMP, and CDCH-UCV. 
that it is a two-point method while the steepest descent method is not. The main idea behind the spectral choice of steplength is that the steepest descent method is very slow but it can be accelerated by taking, instead of the stepsize that comes from the minimization of the function along the gradient of the current iteration, the one that comes from the one-dimensional minimization at the previous step. See Glunt, Hayden, and Raydan [15] for a relationship with the shifted power method to approximate eigenvalues and eigenvectors and also for an interesting chemistry application. See also Raydan [27] for a combination of the spectral choice of steplength with nonmonotone line search techniques to solve unconstrained minimization problems. A successful application of this technique can be found in [5].

Therefore, it is natural and rather easy to transport the spectral gradient idea with a nonmonotone line search to the projected gradient case in order to speed up the convergence of the projected gradient method. In particular, in this work we extend the practical version of Bertsekas [2] that enforces an Armijo-type condition along the curvilinear projection path. This practical version is based on the original version proposed by Goldstein [16] and Levitin and Polyak [19]. We also apply the new ingredients to the feasible continuous projected path that will be properly defined in section 2 .

The convergence properties of the projected gradient method for different choices of stepsize have been extensively studied. See, e.g., [2, 3, 7, 11, 16, 19, 22, 30]. For an interesting review of the different convergence results that have been obtained under different assumptions, see Calamai and Moré [7]. For a complete survey see Dunn [12].

In section 2 of this paper we define the spectral projected gradient algorithms and prove global convergence results. In section 3 we present numerical experiments. This set of experiments shows that, in fact, the spectral choice of the steplength represents considerable progress in relation to constant choices and that the nonmonotone framework is useful. Some final remarks are presented in section 4. In particular, we elaborate on the relationship between the spectral gradient method and the quasiNewton family of methods.

2. Nonmonotone gradient-projection algorithms. The nonmonotone spectral gradient-projection algorithms introduced in this section apply to problems of the form

$$
\text { minimize } f(x) \text { subject to } \quad x \in \Omega \text {, }
$$

where $\Omega$ is a closed convex set in $\mathbb{R}^{n}$. Throughout this paper we assume that $f$ is defined and has continuous partial derivatives on an open set that contains $\Omega$. Throughout this work $\|\cdot\|$ denotes the 2 -norm of vectors and matrices, although in some cases it can be replaced by an arbitrary norm.

Given $z \in \mathbb{R}^{n}$ we define $P(z)$ as the orthogonal projection on $\Omega$. We denote $g(x)=\nabla f(x)$. The algorithms start with $x_{0} \in \Omega$ and use an integer $M \geq 1$, a small parameter $\alpha_{\min }>0$, a large parameter $\alpha_{\max }>\alpha_{\min }$, a sufficient decrease parameter $\gamma \in(0,1)$, and safeguarding parameters $0<\sigma_{1}<\sigma_{2}<1$. Initially, $\alpha_{0} \in\left[\alpha_{\min }, \alpha_{\max }\right]$ is arbitrary. Given $x_{k} \in \Omega$ and $\alpha_{k} \in\left[\alpha_{\min }, \alpha_{\max }\right]$, Algorithms 2.1 and 2.2 describe how to obtain $x_{k+1}$ and $\alpha_{k+1}$ and when to terminate the process.

AlGORITHM 2.1.

Step 1. Detect whether the current point is stationary

If $\left\|P\left(x_{k}-g\left(x_{k}\right)\right)-x_{k}\right\|=0$, stop, declaring that $x_{k}$ is stationary.

Step 2. Backtracking

Step 2.1. Set $\lambda \leftarrow \alpha_{k}$. 
Step 2.2. Set $x_{+}=P\left(x_{k}-\lambda g\left(x_{k}\right)\right)$.

Step 2.3. If

$$
f\left(x_{+}\right) \leq \max _{0 \leq j \leq \min \{k, M-1\}} f\left(x_{k-j}\right)+\gamma\left\langle x_{+}-x_{k}, g\left(x_{k}\right)\right\rangle,
$$

then define $\lambda_{k}=\lambda, x_{k+1}=x_{+}, s_{k}=x_{k+1}-x_{k}, y_{k}=g\left(x_{k+1}\right)-g\left(x_{k}\right)$, and go to Step 3.

If (1) does not hold, define

$$
\lambda_{\text {new }} \in\left[\sigma_{1} \lambda, \sigma_{2} \lambda\right]
$$

set $\lambda \leftarrow \lambda_{\text {new }}$, and go to Step 2.2 .

Step 3.

Compute $b_{k}=\left\langle s_{k}, y_{k}\right\rangle$.

If $b_{k} \leq 0$, set $\alpha_{k+1}=\alpha_{\max }$; else, compute $a_{k}=\left\langle s_{k}, s_{k}\right\rangle$ and

$$
\alpha_{k+1}=\min \left\{\alpha_{\max }, \max \left\{\alpha_{\min }, a_{k} / b_{k}\right\}\right\} .
$$

The one-dimensional search procedure of Algorithm 2.1 (called SPG1 from now on) takes into account points of the form $P\left(x_{k}-\lambda g\left(x_{k}\right)\right)$ for $\lambda \in\left(0, \alpha_{k}\right]$, which, in general, form a curvilinear path (piecewise linear if $\Omega$ is a polyhedral set). For this reason, the scalar product $\left\langle x_{+}-x_{k}, g\left(x_{k}\right)\right\rangle$ in the nonmonotone Armijo condition (1) must be computed for each trial point $x_{+}$. Moreover, in the SPG1 formulation the distance between two consecutive trial points could be very small or even null in the vicinity of corner points of the set $\Omega$. In fact the distance between the projections of two points on the feasible set can be small, even if the points are distant from each other. Clearly, to evaluate the objective function on two close points represents a bad use of available information. Of course, proximity of two consecutive trial points can be computationally detected at the expense of $O(n)$ operations or comparisons.

These observations motivated us to define Algorithm 2.2. This algorithm is also based on the spectral projected gradient direction $P\left(x_{k}-\alpha_{k} g\left(x_{k}\right)\right)-x_{k}$, with $\alpha_{k}$ as the safeguarded "inverse Rayleigh quotient" $\frac{\left\langle s_{k-1}, s_{k-1}\right\rangle}{\left\langle s_{k-1}, y_{k-1}\right\rangle}$. (Observe that $\frac{\left\langle s_{k-1}, y_{k-1}\right\rangle}{\left\langle s_{k-1}, s_{k-1}\right\rangle}$ is in fact a Rayleigh quotient corresponding to the average Hessian matrix $\int_{0}^{1} \nabla^{2} f\left(x_{k-1}+\right.$ $\left.t s_{k-1}\right) d t$.) However, in the case of rejection of the first trial point, the next ones are computed along the same direction. As a consequence, $\left\langle x_{+}-x_{k}, g\left(x_{k}\right)\right\rangle$ must be computed only at the first trial and the projection operation must be performed only once per iteration. So, Algorithm 2.2, which will be called SPG2 in the rest of the paper, coincides with SPG1 except at the backtracking step, whose description is given below.

Algorithm 2.2.

Step 2 (Backtracking)

Step 2.1. Compute $d_{k}=P\left(x_{k}-\alpha_{k} g\left(x_{k}\right)\right)-x_{k}$. Set $\lambda \leftarrow 1$.

Step 2.2. Set $x_{+}=x_{k}+\lambda d_{k}$.

Step 2.3. If

$$
f\left(x_{+}\right) \leq \max _{0 \leq j \leq \min \{k, M-1\}} f\left(x_{k-j}\right)+\gamma \lambda\left\langle d_{k}, g\left(x_{k}\right)\right\rangle,
$$

then define $\lambda_{k}=\lambda, x_{k+1}=x_{+}, s_{k}=x_{k+1}-x_{k}, y_{k}=g\left(x_{k+1}\right)-g\left(x_{k}\right)$, and go to Step 3. 
If (3) does not hold, define $\lambda_{\text {new }}$ as in (2), set $\lambda \leftarrow \lambda_{\text {new }}$, and go to Step 2.2.

In both algorithms the computation of $\lambda_{\text {new }}$ uses one-dimensional quadratic interpolation and it is safeguarded taking $\lambda \leftarrow \lambda / 2$ when the minimum of the onedimensional quadratic lies outside $[0.1,0.9 \lambda]$. Notice also that the line search conditions (1) and (3) guarantee that the sequence $\left\{x_{k}\right\}$ remains in $\Omega_{0} \equiv\{x \in \Omega: f(x) \leq$ $\left.f\left(x_{0}\right)\right\}$.

It will be useful in our theoretical analysis to define the scaled projected gradient $g_{t}(x)$ as

$$
g_{t}(x)=[P(x-\operatorname{tg}(x))-x]
$$

for all $x \in \Omega, t>0$. If $x$ is an iterate of SPG1 or SPG2 and $t=\alpha_{k}$ the scaled projected gradient is the spectral projected gradient (SPG) that gives the name to our methods. If $t=1$, the scaled projected gradient is the continuous projected gradient whose $\infty$ norm $\left\|g_{1}(x)\right\|_{\infty}$ is used for the termination criterion of the algorithms. In fact, the annihilation of $g_{t}(x)$ is equivalent to the satisfaction of first-order stationary conditions. This property is stated in the following lemma, whose proof is a straightforward consequence of the convexity of $\Omega$.

Lemma 2.1. For all $x \in \Omega, t \in\left(0, \alpha_{\max }\right]$,

(i) $\left\langle g(x), g_{t}(x)\right\rangle \leq-\frac{1}{t}\left\|g_{t}(x)\right\|_{2}^{2} \leq-\frac{1}{\alpha_{\max }}\left\|g_{t}(x)\right\|_{2}^{2}$.

(ii) The vector $g_{t}(\bar{x})$ vanishes if and only if $\bar{x}$ is a constrained stationary point.

Now, let us prove that both algorithms are well defined and have the property that every accumulation point $\bar{x}$ is a constrained stationary point, i.e., that

$$
\langle g(\bar{x}), x-\bar{x}\rangle \geq 0 \text { for all } x \in \Omega .
$$

The proof of our first theorem relies on Proposition 2.3.3 in Bertsekas [3], which is related to the Armijo condition along the projection arc. This proposition was originally shown in [14]. For completeness we include in the next lemma some technical results from [3] that will be used in our proof.

Lemma 2.2. (i) For all $x \in \Omega$ and $z \in \mathbb{R}^{n}$, the function $h:[0, \infty) \rightarrow \mathbb{R}$ given by

$$
h(s)=\frac{\|P(x+s z)-x\|}{s} \text { for all } s>0
$$

is monotonically nonincreasing.

(ii) For all $x \in \Omega$ there exists $s_{x}>0$ such that for all $t \in\left[0, s_{x}\right]$ it holds that

$$
f(P(x-t g(x)))-f(x) \leq \gamma\left\langle g(x), g_{t}(x)\right\rangle .
$$

Proof. See Lemma 2.3.1 and Theorem 2.3.3 (part (a)) in [3].

THEOREM 2.3. Algorithm SPG1 is well defined, and any accumulation point of the sequence $\left\{x_{k}\right\}$ that it generates is a constrained stationary point.

Proof. From Lemma 2.2(ii), we have for all $\lambda \in\left[0, \min \left\{s_{x_{k}}, \alpha_{\min }\right\}\right]$ that

$$
\begin{aligned}
f\left(P\left(x_{k}-\lambda g\left(x_{k}\right)\right)\right)-\max _{0 \leq j \leq M-1} f\left(x_{k-j}\right) & \leq f\left(P\left(x_{k}-\lambda g\left(x_{k}\right)\right)\right)-f\left(x_{k}\right) \\
& \leq \gamma\left\langle g\left(x_{k}\right), g_{\lambda}\left(x_{k}\right)\right\rangle .
\end{aligned}
$$

Therefore, a stepsize satisfying (1) will be found after a finite number of trials, and Algorithm SPG1 is well defined.

Let $\bar{x} \in \Omega$ be an accumulation point of $\left\{x_{k}\right\}$, and relabel $\left\{x_{k}\right\}$ a subsequence converging to $\bar{x}$. We consider two cases. 
Case 1. If inf $\lambda_{k}=0$, then there exists a subsequence $\left\{x_{k}\right\}_{K}$ such that

$$
\lim _{k \in K} \lambda_{k}=0 .
$$

In that case, from the way $\lambda_{k}$ is chosen in (1), there exists an index $\bar{k}$ sufficiently large such that for all $k \geq \bar{k}, k \in K$, there exists $\rho_{k}, 0<\sigma_{1} \leq \rho_{k} \leq \sigma_{2}$, for which $\psi_{k} \equiv \lambda_{k} / \rho_{k}>0$ fails to satisfy condition (1), i.e.,

$$
\begin{gathered}
f\left(P\left(x_{k}-\psi_{k} g\left(x_{k}\right)\right)\right)>\max _{0 \leq j \leq M-1} f\left(x_{k-j}\right)+\gamma\left\langle g\left(x_{k}\right), P\left(x_{k}-\psi_{k} g\left(x_{k}\right)\right)-x_{k}\right\rangle \\
\geq f\left(x_{k}\right)+\gamma\left\langle g\left(x_{k}\right), P\left(x_{k}-\psi_{k} g\left(x_{k}\right)\right)-x_{k}\right\rangle .
\end{gathered}
$$

Therefore, it follows that

$$
f\left(P\left(x_{k}-\psi_{k} g\left(x_{k}\right)\right)\right)-f\left(x_{k}\right)>\gamma\left\langle g\left(x_{k}\right), g_{\psi_{k}}\left(x_{k}\right)\right\rangle .
$$

By the mean value theorem we obtain

$$
f\left(P\left(x_{k}-\psi_{k} g\left(x_{k}\right)\right)\right)-f\left(x_{k}\right)=\left\langle g\left(x_{k}\right), g_{\psi_{k}}\left(x_{k}\right)\right\rangle+\left\langle g\left(\xi_{k}\right)-g\left(x_{k}\right), g_{\psi_{k}}\left(x_{k}\right)\right\rangle,
$$

where $\xi_{k}$ lies along the line segment connecting $x_{k}$ and $P\left(x_{k}-\psi_{k} g\left(x_{k}\right)\right)$.

Combining (4) and (5) we obtain for all $k \in K$ sufficiently large that

$$
(1-\gamma)\left\langle g\left(x_{k}\right), g_{\psi_{k}}\left(x_{k}\right)\right\rangle>\left\langle g\left(x_{k}\right)-g\left(\xi_{k}\right), g_{\psi_{k}}\left(x_{k}\right)\right\rangle .
$$

Using Lemmas 2.1 and 2.2, we have

$$
\left\langle g\left(x_{k}\right), g_{\psi_{k}}\left(x_{k}\right)\right\rangle \leq-\frac{1}{\psi_{k}}\left\|g_{\psi_{k}}\left(x_{k}\right)\right\|_{2}^{2} \leq-\frac{1}{\alpha_{k}}\left\|g_{\alpha_{k}}\left(x_{k}\right)\right\|_{2}\left\|g_{\psi_{k}}\left(x_{k}\right)\right\|_{2},
$$

where $\alpha_{k}$ is the initial stepsize at iteration $k$. Combining (6) and (7) and using the Schwartz inequality, we obtain for $k \in K$ sufficiently large

$$
\begin{gathered}
\frac{(1-\gamma)}{\alpha_{k}}\left\|g_{\alpha_{k}}\left(x_{k}\right)\right\|_{2}\left\|g_{\psi_{k}}\left(x_{k}\right)\right\|_{2}<\left\langle g\left(\xi_{k}\right)-g\left(x_{k}\right), g_{\psi_{k}}\left(x_{k}\right)\right\rangle \\
\leq\left\|g\left(\xi_{k}\right)-g\left(x_{k}\right)\right\|_{2}\left\|g_{\psi_{k}}\left(x_{k}\right)\right\|_{2} .
\end{gathered}
$$

Using that $\left\|g_{\psi_{k}}\left(x_{k}\right)\right\|_{2} \neq 0$, we have

$$
\frac{(1-\gamma)}{\alpha_{k}}\left\|g_{\alpha_{k}}\left(x_{k}\right)\right\|_{2}<\left\|g\left(\xi_{k}\right)-g\left(x_{k}\right)\right\|_{2}
$$

Since $\psi_{k} \rightarrow 0$ and $x_{k} \rightarrow \bar{x}$ as $k \rightarrow \infty, k \in K$, then $\xi_{k} \rightarrow \bar{x}$ as $k \rightarrow \infty, k \in K$. Taking a convenient subsequence $\bar{K} \subseteq K$ such that $\left\{\alpha_{k}\right\}$ is convergent to $\bar{\alpha} \in\left[\alpha_{\min }, \alpha_{\max }\right]$, and taking limits in (8) as $k \rightarrow \infty, k \in \bar{K}$, we deduce that

$$
\left\|g_{\bar{\alpha}}(\bar{x})\right\|_{2} \leq 0 \text {. }
$$

Therefore, $g_{\bar{\alpha}}(\bar{x})=0$, and $\bar{x}$ is a constrained stationary point.

Case 2. Assume that inf $\lambda_{k} \geq \rho>0$. Let us suppose by way of contradiction that $\bar{x}$ is not a constrained stationary point. Therefore $\left\|g_{\lambda}(\bar{x})\right\|>0$ for all $\lambda \in\left(0, \alpha_{\max }\right]$. 
By continuity and compactness, there exists $\delta>0$ such that $\left\|g_{\lambda}(\bar{x})\right\| \geq \delta>0$ for all $\lambda \in\left[\rho, \alpha_{\max }\right]$. Using the first part of the proof of the theorem in [17, p. 709], we obtain a monotonically nonincreasing sequence $\left\{f\left(x_{l(k)}\right)\right\}$. Indeed, let $l(k)$ be an integer such that $k-\min \{k, M-1\} \leq l(k) \leq k$ and

$$
f\left(x_{l(k)}\right)=\max _{0 \leq j \leq \min \{k, M-1\}} f\left(x_{k-j}\right) .
$$

From (1) it follows that, for $k>M-1$ (see [17] for details),

$$
f\left(x_{l(k)}\right) \leq f\left(x_{l(l(k)-1)}\right)+\gamma\left\langle g\left(x_{l(k)-1}\right), g_{\lambda_{l(k)-1}}\left(x_{l(k)-1}\right)\right\rangle .
$$

By continuity, for $k \geq \bar{k}$ sufficiently large, $\left\|g_{\lambda}\left(\bar{x}_{k}\right)\right\| \geq \delta / 2$. Hence, using Lemma 2.1, we obtain

$$
f\left(x_{l(k)}\right) \leq f\left(x_{l(l(k)-1)}\right)-\frac{\gamma}{\alpha_{\max }}\left\|g_{\lambda_{l(k)-1}}\left(x_{l(k)-1}\right)\right\|_{2}^{2} \leq f\left(x_{l(l(k)-1)}\right)-\frac{\gamma \delta^{2}}{4 \alpha_{\max }} .
$$

When $k \rightarrow \infty$, clearly $f\left(x_{l(k)}\right) \rightarrow-\infty$, which is a contradiction. In fact, $f$ is a continuous function and so $f\left(x_{k}\right)$ converges to $f(\bar{x})$.

THEOREM 2.4. Algorithm SPG2 is well defined, and any accumulation point of the sequence $\left\{x_{k}\right\}$ that it generates is a constrained stationary point.

Proof. If $x_{k}$ is not a constrained stationary point, then by Lemma 2.1

$$
\left\langle g\left(x_{k}\right), d_{k}\right\rangle=\left\langle g\left(x_{k}\right), g_{\alpha_{k}}\left(x_{k}\right)\right\rangle \leq-\frac{1}{\alpha_{\max }}\left\|g_{\alpha_{k}}\left(x_{k}\right)\right\|_{2}^{2}<0,
$$

and the search direction is a descent direction. Hence, a stepsize satisfying (3) will be found after a finite number of trials, and Algorithm SPG2 is well defined.

Let $\bar{x} \in \Omega$ be an accumulation point of $\left\{x_{k}\right\}$, and relabel $\left\{x_{k}\right\}$ a subsequence converging to $\bar{x}$. We consider two cases.

Case 1. Assume that inf $\lambda_{k}=0$. Suppose, by contradiction, that $\bar{x}$ is not stationary. By continuity and compactness, there exists $\delta>0$ such that

$$
\left\langle g(\bar{x}), \frac{P(\bar{x}-\alpha g(\bar{x}))-\bar{x}}{\|P(\bar{x}-\alpha g(\bar{x}))-\bar{x}\|}\right\rangle<-\delta \quad \text { for all } \quad \alpha \in\left[\alpha_{\min }, \alpha_{\max }\right] .
$$

This implies that

$$
\left\langle g\left(x_{k}\right), \frac{P\left(x_{k}-\alpha g\left(x_{k}\right)\right)-x_{k}}{\left\|P\left(x_{k}-\alpha g\left(x_{k}\right)\right)-x_{k}\right\|}\right\rangle<-\delta / 2 \quad \text { for all } \alpha \in\left[\alpha_{\min }, \alpha_{\max }\right]
$$

and $k$ large enough on the subsequence that converges to $\bar{x}$.

Since inf $\lambda_{k}=0$, there exists a subsequence $\left\{x_{k}\right\}_{K}$ such that

$$
\lim _{k \in K} \lambda_{k}=0
$$

In that case, from the way $\lambda_{k}$ is chosen in (3), there exists an index $\bar{k}$ sufficiently large such that for all $k \geq \bar{k}, k \in K$, there exists $\rho_{k}, 0<\sigma_{1} \leq \rho_{k} \leq \sigma_{2}$, for which $\lambda_{k} / \rho_{k}>0$ fails to satisfy condition (3); i.e.,

$$
f\left(x_{k}+\frac{\lambda_{k}}{\rho_{k}} d_{k}\right)>\max _{0 \leq j \leq M-1} f\left(x_{k-j}\right)+\gamma \frac{\lambda_{k}}{\rho_{k}}\left\langle g\left(x_{k}\right), d_{k}\right\rangle \geq f\left(x_{k}\right)+\gamma \frac{\lambda_{k}}{\rho_{k}}\left\langle g\left(x_{k}\right), d_{k}\right\rangle .
$$


Hence,

$$
\frac{f\left(x_{k}+\frac{\lambda_{k}}{\rho_{k}} d_{k}\right)-f\left(x_{k}\right)}{\lambda_{k} / \rho_{k}}>\gamma\left\langle g\left(x_{k}\right), d_{k}\right\rangle .
$$

By the mean value theorem, this relation can be written as

$$
\left\langle g\left(x_{k}+t_{k} d_{k}\right), d_{k}\right\rangle>\gamma\left\langle g\left(x_{k}\right), d_{k}\right\rangle \quad \text { for all } k \in K, k \geq \bar{k},
$$

where $t_{k}$ is a scalar in the interval $\left[0, \lambda_{k} / \rho_{k}\right]$ that goes to zero as $k \in K$ goes to infinity.

Taking a convenient subsequence such that $d_{k} /\left\|d_{k}\right\|$ is convergent to $d$, and taking limits in (10), we deduce that $(1-\gamma)\langle g(\bar{x}), d\rangle \geq 0$. (In fact, observe that $\left\{\left\|d_{k}\right\|\right\}_{K}$ is bounded and so $t_{k}\left\|d_{k}\right\| \rightarrow 0$.) Since $(1-\gamma)>0$ and $\left\langle g\left(x_{k}\right), d_{k}\right\rangle<0$ for all $k$, then $\langle g(\bar{x}), d\rangle=0$.

By continuity and the definition of $d_{k}$ this implies that for $k$ large enough on that subsequence we have that

$$
\left\langle g\left(x_{k}\right), \frac{P\left(x_{k}-\alpha_{k} g\left(x_{k}\right)\right)-x_{k}}{\left\|P\left(x_{k}-\alpha_{k} g\left(x_{k}\right)\right)-x_{k}\right\|}\right\rangle>-\delta / 2,
$$

which contradicts (9).

Case 2. Assume that inf $\lambda_{k} \geq \rho>0$. Let us suppose by way of contradiction that $\bar{x}$ is not a constrained stationary point. Therefore $\left\|g_{\lambda}(\bar{x})\right\|>0$ for all $\lambda \in\left(0, \alpha_{\text {max }}\right]$. By continuity and compactness, there exists $\delta>0$ such that $\left\|g_{\lambda}(\bar{x})\right\| \geq \delta>0$ for all $\lambda \in\left[\rho, \alpha_{\max }\right]$.

As in the proof of the second case of Theorem 2.3,

$$
f\left(x_{l(k)}\right)=\max _{0 \leq j \leq \min \{k, M-1\}} f\left(x_{k-j}\right)
$$

is a monotonically nonincreasing sequence. From (3) it follows that, for $k>M-1$,

$$
f\left(x_{l(k)}\right) \leq f\left(x_{l(l(k)-1)}\right)+\gamma \lambda_{l(k)-1}\left\langle g\left(x_{l(k)-1}\right), g_{\alpha_{l(k)-1}}\left(x_{l(k)-1}\right)\right\rangle .
$$

By continuity, for $k \geq \bar{k}$ sufficiently large, $\left\|g_{\alpha_{k}}\left(\overline{x_{k}}\right)\right\| \geq \delta / 2$. Hence, using Lemma 2.1 , we obtain

$$
f\left(x_{l(k)}\right) \leq f\left(x_{l(l(k)-1)}\right)-\frac{\gamma \rho}{\alpha_{\max }}\left\|g_{\alpha_{l(k)-1}}\left(x_{l(k)-1}\right)\right\|_{2}^{2} \leq f\left(x_{l(l(k)-1)}\right)-\frac{\gamma \delta^{2} \rho}{4 \alpha_{\max }} .
$$

When $k \rightarrow \infty$, clearly $f\left(x_{l(k)}\right) \rightarrow-\infty$, which is a contradiction. In fact, $f$ is a continuous function and so $f\left(x_{k}\right)$ converges to $f(\bar{x})$.

3. Numerical results. The algorithms SPG1 and SPG2 introduced in the previous section compute at least one projection on the feasible set $\Omega$ per iteration. Therefore, these algorithms are especially interesting in the case in which this projection is easy to compute. An important situation in which the projection is trivial is when $\Omega$ is an $n$-dimensional box, possibly with some infinite bounds. In fact, good algorithms for box constrained minimization are the essential tool for the development of efficient augmented Lagrangian methods for general nonlinear programming (see $[8,10,13])$. With this in mind, we implemented the spectral projected gradient algorithms for the case in which $\Omega$ is described by bounds on the variables. In order to assess the reliability of SPG algorithms, we tested them against the well-known 
TABLE 1

Problem sets according to the CUTE classification.

\begin{tabular}{|c|c|c|}
\hline Set \# & Objective type & Problem interest \\
\hline \hline 1 & other & academic \\
2 & other & modeling \\
3 & other & real application \\
4 & sum of squares & academic \\
5 & sum of squares & modeling \\
6 & quadratic & academic \\
7 & quadratic & modeling \\
8 & quadratic & real application \\
\hline
\end{tabular}

package LANCELOT [9] using all the bound constrained problems with more than 50 variables from the CUTE [10] collection. Only problem GRIDGENA was excluded from our tables because it gives an "exception error" when evaluated at some point by SPG algorithms. For all the problems with variable dimension, we used the largest dimension that is admissible without modification of the internal variables of the "double large" installation of CUTE.

Altogether, we solved 50 problems. The horizontal lines in Tables $2-5$ divide the CUTE problems into 8 classes according to objective function type (quadratic, sum of squares, other) and problem interest (academic, modeling, real application). All problems are bound constrained only, twice continuously differentiable, and with more than 50 variables. The 8 sets, in the order in which they appear in the tables, are described in Table 1.

In the numerical experiments we used the default options for LANCELOT, i.e.,

- exact-second-derivatives-used,

- bandsolver-preconditioned-cg-solver-used 5,

- exact-cauchy-point-required,

- infinity-norm-trust-region-used,

- gradient-tolerance 1.0D-05.

We are deeply concerned with the reproducibility of the numerical results presented in this paper. For this reason, all the used codes are available by e-mail request to any of the authors, who are also available to discuss computational details.

All the experiments were run in a SPARCstation Sun Ultra 1, with an UltraSPARC 64-bit processor, $167 \mathrm{MHz}$ clock and 128 MBytes of RAM memory. SPG codes are in Fortran77 and were compiled with the optimization compiler option -O4.

For the SPG methods we used $\gamma=10^{-4}, \alpha_{\min }=10^{-30}, \alpha_{\max }=10^{30}, \sigma_{1}=$ $0.1, \sigma_{2}=0.9$, and $\alpha_{0}=1 /\left\|g_{1}\left(x_{0}\right)\right\|_{\infty}$. After running a few problems with $M \in$ $\{5,10,15\}$, we decided to use $M=10$, as the tests did not show meaningful differences. To decide when to stop the execution of the algorithms declaring convergence we used the criterion $\left\|g_{1}\left(x_{k}\right)\right\|_{\infty} \leq 10^{-5}$. We also stopped the execution of SPG when 50,000 iterations or 200,000 function evaluations were completed without achieving convergence.

To complete the numerical insight into the behavior of SPG methods, we also ran the projected gradient algorithm (PGA), which turns out to be identical to SPG1, with the initial choice of steplength $\alpha_{k} \equiv 1$. In this case we implemented both the monotone version of PGA, which corresponds to $M=1$, and the nonmonotone one with $M=10$. The convergence of the nonmonotone version is a particular case of our Theorem 2.3. The performance of the nonmonotone version of PGA, which is more efficient than the monotone version, is reported in Table 2. 
TABLE 2

Performance of nonmonotone $(M=10)$ projected gradient.

\begin{tabular}{|c|c|c|c|c|c|c|c|}
\hline Problem & $n$ & IT & $\mathrm{FE}$ & GE & Time & $f(x)$ & $\left\|g_{1}(x)\right\|_{\infty}$ \\
\hline BDEXP & 5000 & 13065 & 13066 & 13066 & 459.99 & $3.464 \mathrm{D}-03$ & $9.999 \mathrm{D}-06$ \\
\hline EXPLIN & 120 & 30608 & 200001 & 30609 & 15.08 & $-7.238 \mathrm{D}+05$ & $7.768 \mathrm{D}-05$ \\
\hline EXPLIN2 & 120 & 19581 & 126328 & 19582 & 9.87 & $-7.245 \mathrm{D}+05$ & $8.192 \mathrm{D}-06$ \\
\hline EXPQUAD & 120 & 7899 & 200001 & 7900 & 22.06 & $-3.626 \mathrm{D}+06$ & $3.875 \mathrm{D}-03$ \\
\hline MCCORMCK & 10000 & 16080 & 47939 & 16081 & 2755.50 & $-9.133 \mathrm{D}+03$ & $2.485 \mathrm{D}-09$ \\
\hline PROBPENL & 500 & 888 & 10249 & 889 & 11.39 & $3.992 \mathrm{D}-07$ & $7.265 \mathrm{D}-06$ \\
\hline QRTQUAD & 120 & 3464 & 38175 & 3465 & 3.76 & $-3.625 \mathrm{D}+06$ & $5.303 \mathrm{D}-06$ \\
\hline S368 & 100 & 2139 & 12532 & 2140 & 317.55 & $-7.085 \mathrm{D}+01$ & $9.966 \mathrm{D}-06$ \\
\hline HADAMALS & 1024 & 1808 & 11468 & 1809 & 157.88 & $3.067 \mathrm{D}+04$ & $9.611 \mathrm{D}-06$ \\
\hline CHEBYQAD & 50 & 5287 & 50893 & 5288 & 607.89 & $5.386 \mathrm{D}-03$ & $9.918 \mathrm{D}-06$ \\
\hline HS110 & 50 & 1 & 2 & 2 & 0.00 & $-9.990 \mathrm{D}+09$ & $0.000 \mathrm{D}+00$ \\
\hline LINVERSE & 1999 & 19563 & 200001 & 19564 & 1465.91 & $6.820 \mathrm{D}+02$ & $9.202 \mathrm{D}-02$ \\
\hline NONSCOMP & 10000 & 3737 & 25220 & 3738 & 559.04 & $7.632 \mathrm{D}-13$ & $9.933 \mathrm{D}-06$ \\
\hline QR3DLS & 610 & 17272 & 200001 & 17273 & 735.62 & $3.051 \mathrm{D}-01$ & $3.638 \mathrm{D}-01$ \\
\hline SCON1LS & 1002 & 40237 & 200001 & 40238 & 1512.18 & $6.572 \mathrm{D}+01$ & $8.501 \mathrm{D}-02$ \\
\hline DECONVB & 61 & 6536 & 35665 & 6537 & 10.00 & $2.713 \mathrm{D}-03$ & $1.814 \mathrm{D}-06$ \\
\hline BIGGSB1 & 1000 & 50001 & 104775 & 50002 & 190.46 & $1.896 \mathrm{D}-02$ & $1.362 \mathrm{D}-03$ \\
\hline BQPGABIM & 50 & 2222 & 22640 & 2223 & 1.68 & $-3.790 \mathrm{D}-05$ & $9.972 \mathrm{D}-06$ \\
\hline BQPGASIM & 50 & 1247 & 12394 & 1248 & 0.94 & $-5.520 \mathrm{D}-05$ & $9.334 \mathrm{D}-06$ \\
\hline BQPGAUSS & 2003 & 13482 & 200001 & 13483 & 986.07 & $-1.294 \mathrm{D}-01$ & $1.037 \mathrm{D}+00$ \\
\hline CHENHARK & 1000 & 50001 & 173351 & 50002 & 323.09 & $-2.000 \mathrm{D}+00$ & $5.299 \mathrm{D}-04$ \\
\hline CVXBQP1 & 10000 & 1 & 2 & 2 & 0.10 & $2.250 \mathrm{D}+06$ & $0.000 \mathrm{D}+00$ \\
\hline HARKERP2 & 100 & 100 & 304 & 101 & 0.26 & $-5.000 \mathrm{D}-01$ & $0.000 \mathrm{D}+00$ \\
\hline JNLBRNG1 & 15625 & 13681 & 28689 & 13682 & 3332.51 & $-1.806 \mathrm{D}-01$ & $5.686 \mathrm{D}-06$ \\
\hline JNLBRNG2 & 15625 & 21444 & 107760 & 21445 & 8427.10 & $-4.150 \mathrm{D}+00$ & $9.624 \mathrm{D}-06$ \\
\hline JNLBRNGA & 15625 & 12298 & 27172 & 12299 & 2666.47 & $-2.685 \mathrm{D}-01$ & $5.388 \mathrm{D}-06$ \\
\hline JNLBRNGB & 15625 & 32771 & 200001 & 32772 & 12672.71 & $-5.569 \mathrm{D}+00$ & $3.744 \mathrm{D}+00$ \\
\hline NCVXBQP1 & 10000 & 1 & 2 & 2 & 0.10 & $-1.986 \mathrm{D}+10$ & $0.000 \mathrm{D}+00$ \\
\hline NCVXBQP2 & 10000 & 18012 & 200001 & 18013 & 4053.97 & $-1.334 \mathrm{D}+10$ & $5.798 \mathrm{D}-01$ \\
\hline NCVXBQP3 & 10000 & 15705 & 200001 & 15706 & 3955.02 & $-6.559 \mathrm{D}+09$ & $2.609 \mathrm{D}+00$ \\
\hline NOBNDTOR & 14884 & 3649 & 7300 & 3650 & 718.13 & $-4.405 \mathrm{D}-01$ & $8.604 \mathrm{D}-06$ \\
\hline OBSTCLAE & 15625 & 5049 & 11402 & 5050 & 1119.07 & $1.901 \mathrm{D}+00$ & $1.000 \mathrm{D}-05$ \\
\hline OBSTCLAL & 15625 & 2734 & 6838 & 2735 & 634.97 & $1.901 \mathrm{D}+00$ & $9.986 \mathrm{D}-06$ \\
\hline OBSTCLBL & 15625 & 3669 & 9084 & 3670 & 846.45 & $7.296 \mathrm{D}+00$ & $9.995 \mathrm{D}-06$ \\
\hline OBSTCLBM & 15625 & 2941 & 7634 & 2942 & 694.42 & $7.296 \mathrm{D}+00$ & $9.983 \mathrm{D}-06$ \\
\hline OBSTCLBU & 15625 & 3816 & 9403 & 3817 & 880.51 & $7.296 \mathrm{D}+00$ & $9.981 \mathrm{D}-06$ \\
\hline PENTDI & 1000 & 50001 & 199995 & 50002 & 460.38 & $-7.500 \mathrm{D}-01$ & $2.688 \mathrm{D}-05$ \\
\hline TORSION1 & 14884 & 4540 & 9082 & 4541 & 890.47 & $-4.257 \mathrm{D}-01$ & $6.673 \mathrm{D}-06$ \\
\hline TORSION2 & 14884 & 8704 & 17294 & 8705 & 1703.87 & $-4.257 \mathrm{D}-01$ & $6.599 \mathrm{D}-06$ \\
\hline TORSION3 & 14884 & 1941 & 4525 & 1942 & 406.85 & $-1.212 \mathrm{D}+00$ & $9.957 \mathrm{D}-06$ \\
\hline TORSION4 & 14884 & 4273 & 9062 & 4274 & 862.93 & $-1.212 \mathrm{D}+00$ & $9.897 \mathrm{D}-06$ \\
\hline TORSION5 & 14884 & 672 & 1651 & 673 & 144.80 & $-2.859 \mathrm{D}+00$ & $9.813 \mathrm{D}-06$ \\
\hline TORSION6 & 14884 & 1569 & 3322 & 1570 & 316.06 & $-2.859 \mathrm{D}+00$ & $9.908 \mathrm{D}-06$ \\
\hline TORSIONA & 14884 & 4155 & 8312 & 4156 & 953.30 & $-4.184 \mathrm{D}-01$ & $8.980 \mathrm{D}-06$ \\
\hline TORSIONB & 14884 & 8274 & 16417 & 8275 & 1899.52 & $-4.184 \mathrm{D}-01$ & $8.829 \mathrm{D}-06$ \\
\hline TORSIONC & 14884 & 1933 & 4563 & 1934 & 476.48 & $-1.204 \mathrm{D}+00$ & $9.976 \mathrm{D}-06$ \\
\hline TORSIOND & 14884 & 4325 & 9218 & 4326 & 1013.10 & $-1.204 \mathrm{D}+00$ & $9.854 \mathrm{D}-06$ \\
\hline TORSIONE & 14884 & 688 & 1695 & 689 & 172.87 & $-2.851 \mathrm{D}+00$ & $9.727 \mathrm{D}-06$ \\
\hline TORSIONF & 14884 & 1493 & 3143 & 1494 & 349.72 & $-2.851 \mathrm{D}+00$ & $9.712 \mathrm{D}-06$ \\
\hline ODNAMUR & 11130 & 13222 & 200001 & 13223 & 5249.00 & $1.209 \mathrm{D}+04$ & $5.192 \mathrm{D}+00$ \\
\hline
\end{tabular}

The complete performance of LANCELOT on this set of problems is reported in Table 3. In Tables 4 and 5 we show the behavior of SPG1 and SPG2, respectively.

For LANCELOT, we report the number of outer iterations (or function evaluations) (IT out $\left._{-} \mathrm{FE}\right)$, gradient evaluations $(\mathrm{GE})$, conjugate gradient (or inner) iterations 
TABLE 3

Performance of LANCELOT.

\begin{tabular}{|c|c|c|c|c|c|c|c|}
\hline Problem & $n$ & $\mathrm{IT}_{\text {out }}-\mathrm{FE}$ & GE & $\mathrm{IT}_{i n}-\mathrm{CG}$ & Time & $f(x)$ & $\left\|g_{1}(x)\right\|_{\infty}$ \\
\hline$\overline{B D E X P}$ & 5000 & $\overline{10}$ & $\overline{11}$ & 26 & 3.19 & $\overline{1.964 \mathrm{D}-03}$ & $6.167 \mathrm{D}-06$ \\
\hline EXPLIN & 120 & 13 & 14 & 50 & 0.08 & $-7.238 \mathrm{D}+05$ & $5.183 \mathrm{D}-09$ \\
\hline EXPLIN2 & 120 & 11 & 12 & 24 & 0.07 & $-7.245 \mathrm{D}+05$ & $1.012 \mathrm{D}-06$ \\
\hline EXPQUAD & 120 & 18 & 16 & 52 & 0.14 & $-3.626 \mathrm{D}+06$ & $1.437 \mathrm{D}-06$ \\
\hline MCCORMCK & 10000 & 7 & 6 & 5 & 4.71 & $-9.133 \mathrm{D}+03$ & $5.861 \mathrm{D}-06$ \\
\hline PROBPENL & 500 & 1 & 2 & 0 & 0.17 & $3.992 \mathrm{D}-07$ & $3.424 \mathrm{D}-07$ \\
\hline QRTQUAD & 120 & 168 & 137 & 187 & 1.23 & $-3.625 \mathrm{D}+06$ & $3.568 \mathrm{D}-06$ \\
\hline S368 & 100 & 7 & 7 & 11 & 2.19 & $-1.337 \mathrm{D}+02$ & $3.314 \mathrm{D}-06$ \\
\hline HADAMALS & 1024 & 33 & 34 & 5654 & 157.60 & $7.444 \mathrm{D}+02$ & $7.201 \mathrm{D}-06$ \\
\hline CHEBYQAD & 50 & 65 & 48 & 829 & 5.41 & $5.386 \mathrm{D}-03$ & $7.844 \mathrm{D}-06$ \\
\hline HS110 & 50 & 1 & 2 & 0 & 0.02 & $-9.990 \mathrm{D}+09$ & $0.000 \mathrm{D}+00$ \\
\hline LINVERSE & 1999 & 35 & 30 & 2303 & 77.52 & $6.810 \mathrm{D}+02$ & $8.407 \mathrm{D}-06$ \\
\hline NONSCOMP & 10000 & 8 & 9 & 9 & 4.74 & $3.055 \mathrm{D}-14$ & $9.749 \mathrm{D}-09$ \\
\hline QR3DLS & 610 & 255 & 226 & 25036 & 434.02 & $3.818 \mathrm{D}-08$ & $4.051 \mathrm{D}-06$ \\
\hline SCON1LS & 1002 & 1604 & 1372 & 1357 & 56.51 & $7.070 \mathrm{D}-10$ & $8.568 \mathrm{D}-06$ \\
\hline DECONVB & 61 & 17 & 16 & 233 & 0.40 & $1.236 \mathrm{D}-08$ & $2.147 \mathrm{D}-06$ \\
\hline BIGGSB1 & 1000 & 501 & 502 & 500 & 6.17 & $1.500 \mathrm{D}-02$ & $4.441 \mathrm{D}-16$ \\
\hline BQPGABIM & 50 & 3 & 4 & 10 & 0.03 & $-3.790 \mathrm{D}-05$ & $6.120 \mathrm{D}-06$ \\
\hline BQPGASIM & 50 & 3 & 4 & 9 & 0.03 & $-5.520 \mathrm{D}-05$ & $5.733 \mathrm{D}-06$ \\
\hline BQPGAUSS & 2003 & 8 & 9 & 2345 & 42.60 & $-3.626 \mathrm{D}-01$ & $4.651 \mathrm{D}-06$ \\
\hline CHENHARK & 1000 & 205 & 206 & 484 & 5.02 & $-2.000 \mathrm{D}+00$ & $6.455 \mathrm{D}-06$ \\
\hline CVXBQP1 & 10000 & 1 & 2 & 1 & 3.69 & $2.250 \mathrm{D}+06$ & $0.000 \mathrm{D}+00$ \\
\hline HARKERP2 & 100 & 1 & 2 & 2 & 0.11 & $-5.000 \mathrm{D}-01$ & $7.514 \mathrm{D}-13$ \\
\hline JNLBRNG1 & 15625 & 24 & 25 & 1810 & 217.19 & $-1.806 \mathrm{D}-01$ & $4.050 \mathrm{D}-06$ \\
\hline JNLBRNG2 & 15625 & 14 & 15 & 912 & 108.93 & $-4.150 \mathrm{D}+00$ & $9.133 \mathrm{D}-07$ \\
\hline JNLBRNGA & 15625 & 21 & 22 & 1327 & 155.93 & $-2.685 \mathrm{D}-01$ & $1.191 \mathrm{D}-06$ \\
\hline JNLBRNGB & 15625 & 10 & 11 & 329 & 42.58 & $-6.281 \mathrm{D}+00$ & $2.602 \mathrm{D}-06$ \\
\hline NCVXBQP1 & 10000 & 1 & 2 & 0 & 3.27 & $-1.986 \mathrm{D}+10$ & $0.000 \mathrm{D}+00$ \\
\hline NCVXBQP2 & 10000 & 3 & 4 & 407 & 6.62 & $-1.334 \mathrm{D}+10$ & $5.821 \mathrm{D}-11$ \\
\hline NCVXBQP3 & 10000 & 5 & 6 & 360 & 6.67 & $-6.558 \mathrm{D}+09$ & $2.915 \mathrm{D}-06$ \\
\hline NOBNDTOR & 14884 & 36 & 37 & 790 & 117.34 & $-4.405 \mathrm{D}-01$ & $2.758 \mathrm{D}-06$ \\
\hline OBSTCLAE & 15625 & 4 & 5 & 7409 & 1251.08 & $1.901 \mathrm{D}+00$ & $1.415 \mathrm{D}-06$ \\
\hline OBSTCLAL & 15625 & 24 & 25 & 480 & 58.05 & $1.901 \mathrm{D}+00$ & $5.323 \mathrm{D}-06$ \\
\hline OBSTCLBL & 15625 & 18 & 19 & 2761 & 397.58 & $7.296 \mathrm{D}+00$ & $1.996 \mathrm{D}-06$ \\
\hline OBSTCLBM & 15625 & 5 & 6 & 1377 & 233.70 & $7.296 \mathrm{D}+00$ & $2.243 \mathrm{D}-06$ \\
\hline OBSTCLBU & 15625 & 19 & 20 & 787 & 112.55 & $7.296 \mathrm{D}+00$ & $1.529 \mathrm{D}-06$ \\
\hline PENTDI & 1000 & 1 & 2 & 0 & 0.20 & $-7.500 \mathrm{D}-01$ & $0.000 \mathrm{D}+00$ \\
\hline TORSION1 & 14884 & 37 & 38 & 793 & 96.88 & $-4.257 \mathrm{D}-01$ & $1.237 \mathrm{D}-06$ \\
\hline TORSION2 & 14884 & 9 & 10 & 4339 & 722.28 & $-4.257 \mathrm{D}-01$ & $4.337 \mathrm{D}-06$ \\
\hline TORSION3 & 14884 & 19 & 20 & 241 & 27.36 & $-1.212 \mathrm{D}+00$ & $2.234 \mathrm{D}-06$ \\
\hline TORSION4 & 14884 & 15 & 16 & 5639 & 894.13 & $-1.212 \mathrm{D}+00$ & $6.469 \mathrm{D}-07$ \\
\hline TORSION5 & 14884 & 9 & 10 & 72 & 10.48 & $-2.859 \mathrm{D}+00$ & $3.186 \mathrm{D}-06$ \\
\hline TORSION6 & 14884 & 10 & 11 & 4895 & 579.62 & $-2.859 \mathrm{D}+00$ & $8.124 \mathrm{D}-07$ \\
\hline TORSIONA & 14884 & 37 & 38 & 795 & 103.70 & $-4.184 \mathrm{D}-01$ & $9.590 \mathrm{D}-07$ \\
\hline TORSIONB & 14884 & 10 & 11 & 4025 & 722.79 & $-4.184 \mathrm{D}-01$ & $1.329 \mathrm{D}-06$ \\
\hline TORSIONC & 14884 & 19 & 20 & 241 & 29.77 & $-1.205 \mathrm{D}+00$ & $2.236 \mathrm{D}-06$ \\
\hline TORSIOND & 14884 & 9 & 10 & 9134 & 1369.14 & $-1.205 \mathrm{D}+00$ & $5.184 \mathrm{D}-06$ \\
\hline TORSIONE & 14884 & 9 & 10 & 72 & 11.25 & $-2.851 \mathrm{D}+00$ & $3.201 \mathrm{D}-06$ \\
\hline TORSIONF & 14884 & 10 & 11 & 5008 & 631.14 & $-2.851 \mathrm{D}+00$ & $8.796 \mathrm{D}-07$ \\
\hline ODNAMUR & 11130 & 11 & 12 & 26222 & 1416.03 & $9.237 \mathrm{D}+03$ & $7.966 \mathrm{D}-06$ \\
\hline
\end{tabular}

( $\mathrm{IT}_{i n}$-CG), CPU time in seconds (Time), functional value at the final iterate $(f(x))$, and $\infty$-norm of the "continuous projected gradient" at the final iterate $\left(\left\|g_{1}(x)\right\|_{\infty}\right)$. For SPG methods, we report number of iterations (IT), function evaluations (FE), gradient evaluations (GE), CPU time in seconds (Time), best function value found $(f(x))$, 
TABLE 4

Performance of SPG1.

\begin{tabular}{|c|c|c|c|c|c|c|c|}
\hline Problem & $n$ & IT & $\mathrm{FE}$ & GE & Time & $f(x)$ & $\left\|g_{1}(x)\right\|_{\infty}$ \\
\hline BDEXP & 5000 & 12 & 13 & 13 & 0.45 & $2.744 \mathrm{D}-03$ & $7.896 \mathrm{D}-06$ \\
\hline EXPLIN & 120 & 66 & 75 & 67 & 0.01 & $-7.238 \mathrm{D}+05$ & $3.100 \mathrm{D}-06$ \\
\hline EXPLIN2 & 120 & 48 & 54 & 49 & 0.01 & $-7.245 \mathrm{D}+05$ & $9.746 \mathrm{D}-07$ \\
\hline EXPQUAD & 120 & 92 & 107 & 93 & 0.03 & $-3.626 \mathrm{D}+06$ & $4.521 \mathrm{D}-06$ \\
\hline MCCORMCK & 10000 & 16 & 17 & 17 & 1.78 & $-9.133 \mathrm{D}+03$ & $4.812 \mathrm{D}-06$ \\
\hline PROBPENL & 500 & 2 & 7 & 3 & 0.01 & $3.992 \mathrm{D}-07$ & $1.721 \mathrm{D}-07$ \\
\hline QRTQUAD & 120 & 1693 & 5242 & 1694 & 0.74 & $-3.625 \mathrm{D}+06$ & $5.125 \mathrm{D}-06$ \\
\hline S368 & 100 & 8 & 14 & 9 & 0.67 & $-1.200 \mathrm{D}+02$ & $1.566 \mathrm{D}-07$ \\
\hline HADAMALS & 1024 & 33 & 42 & 34 & 1.49 & $3.107 \mathrm{D}+04$ & $4.828 \mathrm{D}-08$ \\
\hline CHEBYQAD & 50 & 970 & 1545 & 971 & 35.52 & $5.386 \mathrm{D}-03$ & $9.993 \mathrm{D}-06$ \\
\hline HS110 & 50 & 1 & 2 & 2 & 0.00 & $-9.990 \mathrm{D}+09$ & $0.000 \mathrm{D}+00$ \\
\hline LINVERSE & 1999 & 1707 & 2958 & 1708 & 45.42 & $6.810 \mathrm{D}+02$ & $9.880 \mathrm{D}-06$ \\
\hline NONSCOMP & 10000 & 43 & 44 & 44 & 2.28 & $3.419 \mathrm{D}-10$ & $7.191 \mathrm{D}-06$ \\
\hline QR3DLS & 610 & 50001 & 106513 & 50002 & 884.18 & $2.118 \mathrm{D}-04$ & $9.835 \mathrm{D}-03$ \\
\hline SCON1LS & 1002 & 50001 & 75083 & 50002 & 882.43 & $1.329 \mathrm{D}+01$ & $7.188 \mathrm{D}-03$ \\
\hline DECONVB & 61 & 1786 & 2585 & 1787 & 1.68 & $4.440 \mathrm{D}-08$ & $9.237 \mathrm{D}-06$ \\
\hline BIGGSB1 & 1000 & 6820 & 11186 & 6821 & 23.15 & $1.621 \mathrm{D}-02$ & $9.909 \mathrm{D}-06$ \\
\hline BQPGABIM & 50 & 30 & 39 & 31 & 0.01 & $-3.790 \mathrm{D}-05$ & $8.855 \mathrm{D}-06$ \\
\hline BQPGASIM & 50 & 32 & 39 & 33 & 0.01 & $-5.520 \mathrm{D}-05$ & $9.100 \mathrm{D}-06$ \\
\hline BQPGAUSS & 2003 & 50001 & 86373 & 50002 & 930.52 & $-3.623 \mathrm{D}-01$ & $1.930 \mathrm{D}-02$ \\
\hline CHENHARK & 1000 & 3563 & 6113 & 3564 & 14.89 & $-2.000 \mathrm{D}+00$ & $9.993 \mathrm{D}-06$ \\
\hline CVXBQP1 & 10000 & 1 & 2 & 2 & 0.10 & $2.250 \mathrm{D}+06$ & $0.000 \mathrm{D}+00$ \\
\hline HARKERP2 & 100 & 33 & 46 & 34 & 0.06 & $-5.000 \mathrm{D}-01$ & $0.000 \mathrm{D}+00$ \\
\hline JNLBRNG1 & 15625 & 1335 & 1897 & 1336 & 283.55 & $-1.806 \mathrm{D}-01$ & $9.624 \mathrm{D}-06$ \\
\hline JNLBRNG2 & 15625 & 1356 & 2121 & 1357 & 296.46 & $-4.150 \mathrm{D}+00$ & $9.738 \mathrm{D}-06$ \\
\hline JNLBRNGA & 15625 & 629 & 933 & 630 & 116.77 & $-2.685 \mathrm{D}-01$ & $9.809 \mathrm{D}-06$ \\
\hline JNLBRNGB & 15625 & 8531 & 13977 & 8532 & 1635.15 & $-6.281 \mathrm{D}+00$ & $9.903 \mathrm{D}-06$ \\
\hline NCVXBQP1 & 10000 & 1 & 2 & 2 & 0.10 & $-1.986 \mathrm{D}+10$ & $0.000 \mathrm{D}+00$ \\
\hline NCVXBQP2 & 10000 & 60 & 83 & 61 & 3.47 & $-1.334 \mathrm{D}+10$ & $8.219 \mathrm{D}-06$ \\
\hline NCVXBQP3 & 10000 & 112 & 118 & 113 & 5.31 & $-6.558 \mathrm{D}+09$ & $6.019 \mathrm{D}-06$ \\
\hline NOBNDTOR & 14884 & 568 & 817 & 569 & 99.62 & $-4.405 \mathrm{D}-01$ & $9.390 \mathrm{D}-06$ \\
\hline OBSTCLAE & 15625 & 749 & 1028 & 750 & 136.98 & $1.901 \mathrm{D}+00$ & $7.714 \mathrm{D}-06$ \\
\hline OBSTCLAL & 15625 & 290 & 411 & 291 & 53.56 & $1.901 \mathrm{D}+00$ & $7.261 \mathrm{D}-06$ \\
\hline OBSTCLBL & 15625 & 354 & 500 & 355 & 65.52 & $7.296 \mathrm{D}+00$ & $9.024 \mathrm{D}-06$ \\
\hline OBSTCLBM & 15625 & 249 & 343 & 250 & 45.74 & $7.296 \mathrm{D}+00$ & $9.139 \mathrm{D}-06$ \\
\hline OBSTCLBU & 15625 & 325 & 468 & 326 & 60.44 & $7.296 \mathrm{D}+00$ & $7.329 \mathrm{D}-06$ \\
\hline PENTDI & 1000 & 12 & 14 & 13 & 0.07 & $-7.500 \mathrm{D}-01$ & $8.523 \mathrm{D}-07$ \\
\hline TORSION1 & 14884 & 574 & 832 & 575 & 101.00 & $-4.257 \mathrm{D}-01$ & $9.525 \mathrm{D}-06$ \\
\hline TORSION2 & 14884 & 586 & 862 & 587 & 102.79 & $-4.257 \mathrm{D}-01$ & $9.712 \mathrm{D}-06$ \\
\hline TORSION3 & 14884 & 231 & 350 & 232 & 41.47 & $-1.212 \mathrm{D}+00$ & $9.593 \mathrm{D}-06$ \\
\hline TORSION4 & 14884 & 190 & 259 & 191 & 32.66 & $-1.212 \mathrm{D}+00$ & $8.681 \mathrm{D}-06$ \\
\hline TORSION5 & 14884 & 83 & 101 & 84 & 13.84 & $-2.859 \mathrm{D}+00$ & $9.169 \mathrm{D}-06$ \\
\hline TORSION6 & 14884 & 82 & 97 & 83 & 13.58 & $-2.859 \mathrm{D}+00$ & $7.987 \mathrm{D}-06$ \\
\hline TORSIONA & 14884 & 722 & 1057 & 723 & 147.94 & $-4.184 \mathrm{D}-01$ & $8.590 \mathrm{D}-06$ \\
\hline TORSIONB & 14884 & 527 & 765 & 528 & 107.52 & $-4.184 \mathrm{D}-01$ & $9.475 \mathrm{D}-06$ \\
\hline TORSIONC & 14884 & 190 & 270 & 191 & 38.50 & $-1.204 \mathrm{D}+00$ & $9.543 \mathrm{D}-06$ \\
\hline TORSIOND & 14884 & 241 & 340 & 242 & 48.43 & $-1.204 \mathrm{D}+00$ & $9.575 \mathrm{D}-06$ \\
\hline TORSIONE & 14884 & 57 & 76 & 58 & 11.42 & $-2.851 \mathrm{D}+00$ & $8.700 \mathrm{D}-06$ \\
\hline TORSIONF & 14884 & 67 & 85 & 68 & 14.16 & $-2.851 \mathrm{D}+00$ & $9.352 \mathrm{D}-06$ \\
\hline ODNAMUR & 11130 & 50001 & 82984 & 50002 & 4187.58 & $9.250 \mathrm{D}+03$ & $9.690 \mathrm{D}-02$ \\
\hline
\end{tabular}

and $\infty$-norm of the continuous projected gradient at the final iterate $\left(\left\|g_{1}(x)\right\|_{\infty}\right)$.

The numerical results of 10 problems deserve special comments:

(1) $\operatorname{BDEXP}(n=5,000)$ : LANCELOT obtained $f(x)=1.964 \times 10^{-3}$ in 3.19 seconds, whereas SPG1 and SPG2 got $f(x)=2.744 \times 10^{-3}$ in 0.45 seconds. Since the gradient norm is computed in LANCELOT only after each outer 
TABLE 5

Performance of SPG2.

\begin{tabular}{|c|c|c|c|c|c|c|c|}
\hline Problem & $n$ & IT & FE & GE & Time & $f(x)$ & $\left\|g_{1}(x)\right\|_{\infty}$ \\
\hline BDEXP & 5000 & 12 & 13 & 13 & 0.45 & $2.744 \mathrm{D}-03$ & $7.896 \mathrm{D}-06$ \\
\hline EXPLIN & 120 & 54 & 57 & 55 & 0.01 & $-7.238 \mathrm{D}+05$ & $4.482 \mathrm{D}-06$ \\
\hline EXPLIN2 & 120 & 56 & 59 & 57 & 0.01 & $-7.245 \mathrm{D}+05$ & $5.633 \mathrm{D}-06$ \\
\hline EXPQUAD & 120 & 92 & 110 & 93 & 0.03 & $-3.626 \mathrm{D}+06$ & $7.644 \mathrm{D}-06$ \\
\hline MCCORMCK & 10000 & 16 & 17 & 17 & 1.78 & $-9.133 \mathrm{D}+03$ & $4.812 \mathrm{D}-06$ \\
\hline PROBPENL & 500 & 2 & 6 & 3 & 0.01 & $3.992 \mathrm{D}-07$ & $1.022 \mathrm{D}-07$ \\
\hline QRTQUAD & 120 & 598 & 1025 & 599 & 0.19 & $-3.624 \mathrm{D}+06$ & $8.049 \mathrm{D}-06$ \\
\hline S368 & 100 & 16 & 19 & 17 & 1.15 & $-1.403 \mathrm{D}+02$ & $1.963 \mathrm{D}-08$ \\
\hline HADAMALS & 1024 & 30 & 42 & 31 & 1.27 & $3.107 \mathrm{D}+04$ & $2.249 \mathrm{D}-07$ \\
\hline CHEBYQAD & 50 & 1240 & 2015 & 1241 & 45.73 & $5.386 \mathrm{D}-03$ & $8.643 \mathrm{D}-06$ \\
\hline HS110 & 50 & 1 & 2 & 2 & 0.00 & $-9.990 \mathrm{D}+09$ & $0.000 \mathrm{D}+00$ \\
\hline LINVERSE & 1999 & 1022 & 1853 & 1023 & 26.75 & $6.810 \mathrm{D}+02$ & $8.206 \mathrm{D}-06$ \\
\hline NONSCOMP & 10000 & 43 & 44 & 44 & 2.22 & $3.419 \mathrm{D}-10$ & $7.191 \mathrm{D}-06$ \\
\hline QR3DLS & 610 & 50001 & 107915 & 50002 & 869.25 & $2.312 \mathrm{D}-04$ & $1.599 \mathrm{D}-02$ \\
\hline SCON1LS & 1002 & 50001 & 76011 & 50002 & 835.10 & $1.416 \mathrm{D}+01$ & $1.410 \mathrm{D}-02$ \\
\hline DECONVB & 61 & 1670 & 2560 & 1671 & 1.38 & $4.826 \mathrm{D}-08$ & $9.652 \mathrm{D}-06$ \\
\hline BIGGSB1 & 1000 & 7571 & 12496 & 7572 & 24.41 & $1.626 \mathrm{D}-02$ & $9.999 \mathrm{D}-06$ \\
\hline BQPGABIM & 50 & 24 & 37 & 25 & 0.01 & $-3.790 \mathrm{D}-05$ & $8.640 \mathrm{D}-06$ \\
\hline BQPGASIM & 50 & 33 & 46 & 34 & 0.01 & $-5.520 \mathrm{D}-05$ & $8.799 \mathrm{D}-06$ \\
\hline BQPGAUSS & 2003 & 50001 & 87102 & 50002 & 902.26 & $-3.624 \mathrm{D}-01$ & $2.488 \mathrm{D}-03$ \\
\hline CHENHARK & 1000 & 2464 & 4162 & 2465 & 9.60 & $-2.000 \mathrm{D}+00$ & $9.341 \mathrm{D}-06$ \\
\hline CVXBQP1 & 10000 & 1 & 2 & 2 & 0.10 & $2.250 \mathrm{D}+06$ & $2.776 \mathrm{D}-17$ \\
\hline HARKERP2 & 100 & 33 & 46 & 34 & 0.06 & $-5.000 \mathrm{D}-01$ & $1.110 \mathrm{D}-16$ \\
\hline JNLBRNG1 & 15625 & 1664 & 2524 & 1665 & 349.19 & $-1.806 \mathrm{D}-01$ & $6.265 \mathrm{D}-06$ \\
\hline JNLBRNG2 & 15625 & 1443 & 2320 & 1444 & 309.22 & $-4.150 \mathrm{D}+00$ & $9.665 \mathrm{D}-06$ \\
\hline JNLBRNGA & 15625 & 981 & 1530 & 982 & 180.92 & $-2.685 \mathrm{D}-01$ & $6.687 \mathrm{D}-06$ \\
\hline JNLBRNGB & 15625 & 17014 & 28077 & 17015 & 3180.14 & $-6.281 \mathrm{D}+00$ & $1.000 \mathrm{D}-05$ \\
\hline NCVXBQP1 & 10000 & 1 & 2 & 2 & 0.10 & $-1.986 \mathrm{D}+10$ & $2.776 \mathrm{D}-17$ \\
\hline NCVXBQP2 & 10000 & 84 & 93 & 85 & 4.00 & $-1.334 \mathrm{D}+10$ & $2.956 \mathrm{D}-06$ \\
\hline NCVXBQP3 & 10000 & 111 & 117 & 112 & 5.13 & $-6.558 \mathrm{D}+09$ & $2.941 \mathrm{D}-06$ \\
\hline NOBNDTOR & 14884 & 566 & 834 & 567 & 98.52 & $-4.405 \mathrm{D}-01$ & $8.913 \mathrm{D}-06$ \\
\hline OBSTCLAE & 15625 & 639 & 936 & 640 & 116.86 & $1.901 \mathrm{D}+00$ & $9.343 \mathrm{D}-06$ \\
\hline OBSTCLAL & 15625 & 176 & 243 & 177 & 31.69 & $1.901 \mathrm{D}+00$ & $6.203 \mathrm{D}-06$ \\
\hline OBSTCLBL & 15625 & 321 & 460 & 322 & 58.49 & $7.296 \mathrm{D}+00$ & $3.731 \mathrm{D}-06$ \\
\hline OBSTCLBM & 15625 & 143 & 192 & 144 & 25.63 & $7.296 \mathrm{D}+00$ & $8.294 \mathrm{D}-06$ \\
\hline OBSTCLBU & 15625 & 311 & 449 & 312 & 56.72 & $7.296 \mathrm{D}+00$ & $9.703 \mathrm{D}-06$ \\
\hline PENTDI & 1000 & 1 & 3 & 2 & 0.01 & $-7.500 \mathrm{D}-01$ & $0.000 \mathrm{D}+00$ \\
\hline TORSION1 & 14884 & 685 & 1023 & 686 & 119.38 & $-4.257 \mathrm{D}-01$ & $9.404 \mathrm{D}-06$ \\
\hline TORSION2 & 14884 & 728 & 1117 & 729 & 127.62 & $-4.257 \mathrm{D}-01$ & $9.616 \mathrm{D}-06$ \\
\hline TORSION3 & 14884 & 183 & 264 & 184 & 31.72 & $-1.212 \mathrm{D}+00$ & $6.684 \mathrm{D}-06$ \\
\hline TORSION4 & 14884 & 226 & 325 & 227 & 38.99 & $-1.212 \mathrm{D}+00$ & $9.398 \mathrm{D}-06$ \\
\hline TORSION5 & 14884 & 73 & 105 & 74 & 12.68 & $-2.859 \mathrm{D}+00$ & $8.751 \mathrm{D}-06$ \\
\hline TORSION6 & 14884 & 63 & 75 & 64 & 10.39 & $-2.859 \mathrm{D}+00$ & $9.321 \mathrm{D}-06$ \\
\hline TORSIONA & 14884 & 496 & 756 & 497 & 100.13 & $-4.184 \mathrm{D}-01$ & $6.442 \mathrm{D}-06$ \\
\hline TORSIONB & 14884 & 584 & 866 & 585 & 116.70 & $-4.184 \mathrm{D}-01$ & $7.917 \mathrm{D}-06$ \\
\hline TORSIONC & 14884 & 247 & 350 & 248 & 48.81 & $-1.204 \mathrm{D}+00$ & $9.683 \mathrm{D}-06$ \\
\hline TORSIOND & 14884 & 226 & 317 & 227 & 44.62 & $-1.204 \mathrm{D}+00$ & $9.467 \mathrm{D}-06$ \\
\hline TORSIONE & 14884 & 65 & 89 & 66 & 12.90 & $-2.851 \mathrm{D}+00$ & $9.459 \mathrm{D}-06$ \\
\hline TORSIONF & 14884 & 68 & 84 & 69 & 13.07 & $-2.851 \mathrm{D}+00$ & $9.302 \mathrm{D}-06$ \\
\hline ODNAMUR & 11130 & 50001 & 80356 & 50002 & 3927.97 & $9.262 \mathrm{D}+03$ & $4.213 \mathrm{D}-01$ \\
\hline
\end{tabular}

iteration, which involves considerable computer effort, LANCELOT usually stops at points where this norm is considerably smaller than the tolerance $10^{-5}$. On the other hand, SPG methods, which test the projected gradient more frequently, stop when $\left\|g_{1}(x)\right\|_{\infty}$ is slightly smaller than that tolerance. In a small number of cases this affects the quality of the solution, reflected in 
the objective function value.

(2) S368 $(n=100)$ : LANCELOT, SPG1, and SPG2 arrived at different solutions, the best of which was the one obtained by SPG2. SPG1 was the winner in terms of computer time.

(3) HADAMALS $(n=1,024)$ : LANCELOT obtained $f(x)=74.44$ in 157.6 seconds. SPG1 and SPG2 obtained stationary points with $f(x)=31,070$ in less than 2 seconds.

(4) NONSCOMP $(n=10,000)$ : As in BDEXP, the SPG methods found a solution slightly worse than the one found by LANCELOT but used less computer time.

(5) QR3DLS $(n=610)$ : LANCELOT found a better solution $\left(f(x) \approx 4 \times 10^{-8}\right.$ against $f(x) \approx 2.3 \times 10^{-4}$ ) and used less computer time than the SPG methods.

(6) SCON1LS $(n=1,002)$ : LANCELOT found the solution whereas the SPG methods did not converge after 50,000 iterations.

(7) DECONVB $(n=61)$ : LANCELOT found the (slightly) best solution and used less computer time than the SPG methods.

(8) BIGGSB1 $(n=1,000)$ : LANCELOT found $f(x)=0.015$ in 6.17 seconds, whereas the SPG methods got $f(x) \approx 0.016$ in $\approx 24$ seconds.

(9) BQPGAUSS $(n=2,003)$ : LANCELOT beat SPG methods in this problem, in terms of both computer time and quality of solution.

(10) ODNAMUR $(n=11,130)$ : LANCELOT obtained a better solution than the SPG methods for this problem and used less computer time.

Four of the problems considered above (QR3DLS, SCON1LS, BQPGAUSS, and ODNAMUR) can be considered failures of both SPG methods, since convergence to a stationary point was not attained after 50,000 iterations. In the four cases, the final point seems to be in the local attraction basin of a local minimizer, but local convergence is very slow. In fact, in the first three problems, the final projected gradient norm is $\approx 10^{-2}$, and in ODNAMUR the difference between $f(x)$ and its optimal value is $\approx 0.1 \%$. Slow convergence of SPG methods when the Hessian at the local minimizer is very ill conditioned is expected, and preconditioning schemes tend to alleviate this inconvenient. See [21].

In the remaining 40 problems, LANCELOT, SPG1, and SPG2 found the same solutions. In terms of computer time, SPG1 was faster than LANCELOT in 29 problems $(72.5 \%)$ and SPG2 outperformed LANCELOT also in 29 problems. There are no meaningful differences between the performances of SPG1 and SPG2.

Excluding problems where the difference in CPU time was less than 10\%, SPG1 beat LANCELOT 28-9 and SPG2 beat LANCELOT 28-11.

Excluding, from the 40 problems above, the ones in which the 3 algorithms converged in less than 1 second, we are left with 31 problems. Considering this set, SPG1 beat LANCELOT 20-11 (or 19-9 if we exclude, again, differences smaller than 10\%) and SPG2 beat LANCELOT 20-11 (or 19-11).

As we mentioned above, we also implemented the projected gradient algorithm PGA, using the same framework as SPG in terms of interpolation schemes, both with monotone and nonmonotone strategies. The performance of both alternatives is very poor, in comparison to the algorithms SPG1 and SPG2 and other box-constraint minimizers. The performance of the nonmonotone version is given in Table 2. This confirms that the spectral choice of the steplength is the essential feature that puts efficiency in the projected gradient methodology. 
4. Final remarks. It is customary to interpret the first trial step of a minimization algorithm as the minimizer of a quadratic model $q(x)$ on the feasible region or an approximation to it. It is always imposed that the first-order information at the current point should coincide with the first order information of the quadratic model. So, the quadratic approximation at $x_{k+1}$ should be

$$
q(x)=\frac{1}{2}\left\langle x-x_{k+1}, B_{k+1}\left(x-x_{k+1}\right)\right\rangle+\left\langle g\left(x_{k+1}\right), x-x_{k+1}\right\rangle+f\left(x_{k+1}\right)
$$

and

$$
\nabla q(x)=B_{k+1}\left(x-x_{k+1}\right)+g\left(x_{k+1}\right) .
$$

Secant methods are motivated by the interpolation condition $\nabla f\left(x_{k}\right)=\nabla q\left(x_{k}\right)$. Let us impose here the weaker condition

$$
D_{s_{k}} q\left(x_{k}\right)=D_{s_{k}} f\left(x_{k}\right),
$$

where $D_{d} \varphi(x)$ denotes the directional derivative of $\varphi$ along the direction $d$ (so $D_{d} \varphi(x)=$ $\langle\nabla \varphi(x), d\rangle)$. A short calculation shows that condition (11) is equivalent to

$$
\left\langle s_{k}, B_{k+1} s_{k}\right\rangle=\left\langle s_{k}, y_{k}\right\rangle .
$$

Clearly, the spectral choice

$$
B_{k+1}=\frac{\left\langle s_{k}, y_{k}\right\rangle}{\left\langle s_{k}, s_{k}\right\rangle} I
$$

(where $I$ is the identity matrix) satisfies (12). Now, suppose that $z$ is orthogonal to $s_{k}$ and that $x$ belongs to $\mathcal{L}_{k}$, the line determined by $x_{k}$ and $x_{k+1}$. Computing the directional derivative of $q$ along $z$ at any point $x \in \mathcal{L}_{k}$, and using (13), we obtain

$$
D_{z} q(x)=\left\langle B_{k+1}\left(x-x_{k+1}\right)+g\left(x_{k+1}\right), z\right\rangle=\left\langle g\left(x_{k+1}\right), z\right\rangle=D_{z} f\left(x_{k+1}\right) .
$$

Moreover, the properties (12) and

$$
D_{z} q(x)=D_{z} f\left(x_{k+1}\right) \quad \text { for all } \quad x \in \mathcal{L}_{k} \text { and } z \perp s_{k}
$$

imply that $s_{k}$ is an eigenvector of $B_{k+1}$ with eigenvalue $\left\langle s_{k}, y_{k}\right\rangle /\left\langle s_{k}, s_{k}\right\rangle$. Clearly, (13) is the most simple choice that satisfies this property. Another remarkable property of (13) is that the resulting algorithms turn out to be invariant under change of scale of both $f$ and the independent variables.

In contrast to the property (14), satisfied by the spectral choice of $B_{k+1}$, models generated by the secant choice have the property that the directional derivatives of the model coincide with the directional derivatives of the objective function at $x_{k}$. Property (14) says that the model was chosen in such a way that the first order information with respect to orthogonal directions to $s_{k}$ is the same as the first order information of the true objective function at $x_{k+1}$ for all the points on the line $\mathcal{L}_{k}$. This means that first order information at the current point is privileged in the construction of the quadratic model, in relation to second order information that comes from the previous iteration. Perhaps this is one of the reasons underlying the unexpected efficiency of spectral gradient algorithms in relation to some rather arbitrary secant methods. Needless to say, the special form of $B_{k+1}$ trivializes the problem of 
minimizing the model on the feasible set when this is simple enough, a fact that is fully exploited in SPG1 and SPG2.

Boxes are not the only type of sets on which it is trivial to project. The normconstrained regularization problem [18, 23, 24, 32], defined by

$$
\text { minimize } f(x) \text { subject to } x^{T} A x \leq r,
$$

where $A$ is symmetric positive definite, can be reduced to ball constrained minimization by a change of variables and, in this case, projections can be trivially computed. A particular case of (15) is the classical trust-region subproblem, where $f$ is quadratic. Recently (see $[20,25]$ ) procedures for escaping from nonglobal stationary points of this problem have been found, and so it becomes increasingly important to obtain fast algorithms for finding critical points, especially in the large-scale case. (See $[28,29,31]$.)

Perhaps the most important characteristic of SPG algorithms is that they are extremely simple to code, to the point that anyone can write her or his own code using any scientific language in a couple of hours. (Fortran, C, and Matlab codes written by the authors are available by request.) Moreover, their extremely low memory requirements make them very attractive for large-scale problems. It is quite surprising that such a simple tool can be competitive with rather elaborate algorithms that use extensively tested subroutines and numerical procedures. The authors would like to encourage readers to write their own codes and to verify for themselves the nice properties of these algorithms in practical situations. Papers [6] and [4] illustrate the use of SPG methods in applications.

Acknowledgment. The authors are indebted to two anonymous referees whose comments helped considerably to improve this paper.

\section{REFERENCES}

[1] J. BARzilai And J. M. Borwein, Two point step size gradient methods, IMA J. Numer. Anal., 8 (1988), pp. 141-148.

[2] D. P. BertseKAs, On the Goldstein-Levitin-Polyak gradient projection method, IEEE Trans. Automat. Control, 21 (1976), pp. 174-184.

[3] D. P. Bertsekas, Nonlinear Programming, Athena Scientific, Belmont, MA, 1995.

[4] E. G. Birgin, R. Biloti, M. Tygel, And L. T. Santos, Restricted optimization: A clue to a fast and accurate implementation of the common reflection surface stack method, J. Appl. Geophys., 42 (1999), pp. 143-155.

[5] E. G. Birgin, I. Chambouleyron, and J. M. Martínez, Estimation of the optical constants and the thickness of thin films using unconstrained optimization, J. Comput. Phys., 151 (1999), pp. 862-880.

[6] E. G. Birgin And Y. G. Evtushenko, Automatic differentiation and spectral projected gradient methods for optimal control problems, Optim. Methods Softw., 10 (1998), pp. 125-146.

[7] P. H. Calamai and J. J. Moré, Projected gradient methods for linearly constrained problems, Math. Programming, 39 (1987), pp. 93-116.

[8] A. R. Conn, N. I. M. Gould, And Ph. L. Toint, Global convergence of a class of trust region algorithms for optimization with simple bounds, SIAM J. Numer. Anal., 25 (1988), pp. 433-460; see also SIAM J. Numer. Anal., 26 (1989), pp. 764-767.

[9] A. R. Conn, N. I. M. Gould, And Ph. L. Toint, LANCELOT: A Fortran Package for LargeScale Nonlinear Optimization (Release A), Springer Ser. Comput. Math. 17, SpringerVerlag, New York, Berlin, Heidelberg, 1992.

[10] A. R. Conn, N. I. M. Gould, AND Ph. L. Toint, A globally convergent augmented Lagrangian algorithm for optimization with general constraints and simple bounds, SIAM J. Numer. Anal., 28 (1991), pp. 545-572.

[11] J. C. Dunn, Global and asymptotic convergence rate estimates for a class of projected gradient processes, SIAM J. Control Optim., 19 (1981), pp. 368-400.

[12] J. C. Dunn, Gradient-related constrained minimization algorithms in function spaces: Convergence properties and computational implications, in Large Scale Optimization: State 
of the Art, W. W. Hager, D. W. Hearn, and P. M. Pardalos, eds., Kluwer, Dordrecht, the Netherlands, 1994

[13] A. Friedlander, J. M. Martínez, and S. A. Santos, A new trust region algorithm for bound constrained minimization, Appl. Math. Optim., 30 (1994), pp. 235-266.

[14] E. M. Gafni and D. P. Bertsekas, Convergence of a Gradient Projection Method, Report LIDS-P-1201, Lab. for Info. and Dec. Systems, MIT, Cambridge, MA, 1982.

[15] W. Glunt, T. L. Hayden, And M. Raydan, Molecular conformations from distance matrices, J. Comput. Chem., 14 (1993), pp. 114-120.

[16] A. A. Goldstein, Convex programming in Hilbert space, Bull. Amer. Math. Soc., 70 (1964), pp. 709-710.

[17] L. Grippo, F. Lampariello, And S. Lucidi, A nonmonotone line search technique for Newton's method, SIAM J. Numer. Anal., 23 (1986), pp. 707-716.

[18] M. Heinkenschloss, Mesh independence for nonlinear least squares problems with norm constraints, SIAM J. Optim., 3 (1993), pp. 81-117.

[19] E. S. Levitin And B. T. Polyak, Constrained Minimization Problems, USSR Comput. Math. Math. Phys., 6 (1966), pp. 1-50.

[20] S. Lucidi, L. PAlagi, AND M. Roma, On some properties of quadratic programs with a convex quadratic constraint, SIAM J. Optim., 8 (1998), pp. 105-122.

[21] F. Luengo, M. Raydan, W. Glunt, and T. L. Hayden, Preconditioned Spectral Gradient Method for Unconstrained Optimization Problems, Technical Report R.T. 96-08, Computer Science Department, Universidad Central de Venezuela, Caracos Venezuela.

[22] G. P. MCCORMICK AND R. A. TAPIA, The gradient projection method under mild differentiability conditions, SIAM J. Control, 10 (1972), pp. 93-98.

[23] J. M. Martínez and S. A. Santos, A trust region strategy for minimization on arbitrary domains, Math. Programming, 68 (1995), pp. 267-302.

[24] J. M. Martínez And S. A. SANTOS, Convergence results on an algorithm for norm constrained regularization and related problems, RAIRO Rech. Opér., 31 (1997), pp. 269-294.

[25] P. D. TAO AND L. T. H. AN, D.C. optimization algorithm for solving the trust-region subproblem, SIAM J. Optim., 8 (1998), pp. 476-505.

[26] M. RAYDAN, On the Barzilai and Borwein choice of steplength for the gradient method, IMA J. Numer. Anal., 13 (1993), pp. 321-326.

[27] M. RAYDAn, The Barzilai and Borwein gradient method for the large scale unconstrained minimization problem, SIAM J. Optim., 7 (1997), pp. 26-33.

[28] F. Rendl and H. Wolkowicz, A semidefinite framework to trust region subproblems with application to large scale minimization, Math. Programming, 77 (1997), pp. 273-299.

[29] M. Rojas, S. A. Santos And D. C. Sorensen, A new matrix-free algorithm for the large-scale trust-region subproblem, SIAM J. Optim, to appear.

[30] A. Schwartz and E. Polak, Family of projected descent methods for optimization problems with simple bounds, J. Optim. Theory Appl., 92 (1997), pp. 1-31.

[31] D. C. Sorensen, Minimization of a large-scale quadratic function subject to spherical constraint, SIAM J. Optim., 7 (1997), pp. 141-161.

[32] C. R. Vogel, A constrained least squares regularization method for nonlinear ill-posed problems, SIAM J. Control Optim., 28 (1990), pp. 34-49. 